\title{
Plano diretor e planejamento estratégico municipal: introdução teórico-conceitual*
}

\author{
Denis Alcides Rezende** \\ Clovis Ultramari***
}

SUMÁRIO: 1. Introdução; 2 . Os planos e sua interface com o cenário urbano nacional; 3. Referenciais teóricos do plano diretor municipal (PDM); 4. Referenciais teóricos do planejamento estratégico municipal (PEM); 5. Conclusão.

SUMMARY: 1. Introduction; 2. The plans and their interface with the national urban scenario; 3. Theoretical framework of the comprehensive city plan (PDM); 4. Theoretical framework of the strategic city planning (PEM); 5. Conclusion.

PAlAVRas-CHAVE: plano diretor municipal; planejamento estratégico municipal; políticas municipais; gestão municipal; participação cidadã.

KEY WORDS: comprehensive city plan; strategic city plannning; public policy; municipal management; community participation.

Este artigo discute de forma teórico-conceitual o plano diretor municipal e o planejamento estratégico municipal, instrumentos de planejamento em

\footnotetext{
* Artigo recebido em set. 2005 e aceito em abr. 2006.

** Administrador, especialista em magistério superior pela UTP, mestre em informática pela UFPR, doutor em gestão da tecnologia da informação pela UFSC, pós-doutor em administração pela Universidade de São Paulo, professor do curso de Engenharia Ambiental e do Mestrado de Gestão Urbana da Pontifícia Universidade Católica do Paraná (PUC-PR). Bolsista CNPq PDJ. Endereço: Rua Imaculada Conceição, 1155, Parque Tecnológico, bloco 3, 2⿳⼈ㄹ andar — Prado Velho — CEP 80215-901, Curitiba, PR. Brasil. E-mail: denis.rezende@pucpr.br. $* * *$ Arquiteto, doutor em meio ambiente e desenvolvimento urbano pela UFPR, professor no curso de Arquitetura e Urbanismo e no Mestrado em Gestão Urbana da Pontifícia Universidade Católica do Paraná. Endereço: Rua Imaculada Conceição, 1155, Parque Tecnológico, bloco 3, 2ํandar — Prado Velho - CEP 80215-901, Curitiba, PR, Brasil. E-mail: ultramari@yahoo.com.
} 
uso atualmente, que constituem o que se pode chamar de utopias contemporâneas para a questão urbana brasileira. Preliminarmente, contextualizando cada um deles num cenário maior de políticas urbanas. A discussão é fruto de estudos de casos que contaram com a participação dos autores. O plano diretor, mais comumente entendido pela urbanística contemporânea e pela política urbana brasileira, é contextualizado por meio das suas alterações conceituais e processuais após o estabelecimento das diretrizes do Estatuto da Cidade. Já o planejamento estratégico é abordado numa visão atual da administração pública, ainda compromissada com os interesses da maioria da população, mas igualmente obrigando-se a adotar práticas de efetividade até então restritas ao setor privado. Ressalta-se na conclusão que tais instrumentos ora são valorizados, ora esquecidos na prática urbana nacional.

Comprehensive city plan and strategic city planning:

a theoretical conceptual introduction

This paper considers comprehensive and strategic plans important in local public polices: the first — adopted due to a new federal law — the second - implemented because of a more methodological choice - are currently used all over Brazil, and both constitute what could be called a contemporary urban utopia for Brazilian cities. Using case studies, this article discusses how both instruments are implemented, their potential and their limitations, and how they could be integrated. The authors suggest two integration models and one strategic planning method that confirm the possibility of integration and the importance of community participation in the process. They conclude that both instruments are sometimes overrated and others practically ignored by Brazilian urban policies.

\section{Introdução}

Na história recente do planejamento urbano brasileiro observam-se diferentes tentativas de compreensão e de ordenamento do espaço de nossas cidades. Alternam-se conceitos, mecanismos, legislações e prioridades. A mudança de enfoques sobre um mesmo problema, sobretudo aquele que tanto preocupou a questão urbana nas décadas recentes, é emblemática, indicando até mesmo uma mudança referencial no modo de ver a cidade. Utopias urbanas agora parecem dirigir-se não mais a uma urgente eqüidade na apropriação daquilo que a cidade tem a oferecer e daquilo que constitui o mínimo para aí se habi- 
tar; dirigem-se também, sem ignorar os objetivos anteriores, para tentativas de agregar aspectos naturais em um espaço que sempre se caracterizou pela desconstrução da natureza. Outros esforços se dirigem para uma utilização cada vez mais social da propriedade urbana e para uma incremental participação da comunidade. Também se observa a valorização de aspectos positivos que uma cidade venha a ter, indicando propostas estratégicas de utilização das potencialidades para se distinguir num cenário globalmente competitivo. Assim, idéias se alternam e novos instrumentos são buscados para implementálas. Não se fala aqui de passadismos (Alphandéry et al., 1992), mas de simples alternância de idéias e propostas no tempo, acreditando-se na defesa de valores que não devem envelhecer.

As questões físico-territoriais, econômicas, financeiras, políticas, socioambientais e de gestão têm constantemente desafiado os municípios, requerendo um avanço nas técnicas de planejamento até então desenvolvidas pelo governo local. Equilibrar os diferentes interesses que se apresentam em cada uma dessas temáticas e garantir a efetiva participação comunitária parece ser o desafio maior da administração pública local. Diante dessas necessidades e relevâncias, a administração pública municipal demanda competência e efetividade dos seus gestores que devem se atualizar e agir por meio de instrumentos técnicos, modernos e práticos de planejamento e de gestão.

O plano diretor municipal (PDM) e o planejamento estratégico municipal (PEM) são instrumentos de planejamento e gestão de municípios e prefeituras, considerados, atualmente, de importância inquestionável. A realização de tais instrumentos deve mesmo ser compatibilizada com regulamentos de ordem superior, tais como a própria Constituição Federal, a Lei de Responsabilidade Fiscal e o Estatuto da Cidade. No caso do PDM, o Estatuto da Cidade (2001) impõe não apenas o que se deve buscar com esse instrumento, mas avança inclusive para determinações de ordem metodológica e operacional:

Art. 42. O plano diretor deverá conter no mínimo:

I - a delimitação das áreas urbanas onde poderá ser aplicado o parcelamento, edificação ou utilização compulsórios, considerando a existência de infra-estrutura e de demanda para utilização, na forma do art. 5ำ desta Lei;

II - disposições requeridas pelos arts. 25, 28, 29, 32 e 35 desta Lei;

III - sistema de acompanhamento e controle.

Além das determinações constantes no Estatuto da Cidade, governos estaduais e o próprio governo federal brasileiro, por meio de editais públicos de financiamento de PDMs, têm imposto regras de realização desse tipo de 
plano de maneira bastante genérica para seus territórios. No caso do Paraná, por exemplo, que exigiu, em decreto governamental, a elaboração de PDMs para todos os seus 399 municípios, independentemente dos parâmetros adotados no Estatuto, os termos de referência igualam realidades diferentes.

Art. 1ํ. O Estado do Paraná somente firmará convênios de financiamento de obras de infra-estrutura e serviços com municípios que obedecerem aos seguintes requisitos:

a) municípios que já possuam planos diretores aprovados pelas respectivas câmaras municipais; e

b) aos municípios que executarem com recursos próprios ou financiarem prioritariamente planos diretores ou planos de zoneamento, em conformidade com o que estabelece o estatuto das cidades, para elaboração em até 180 (cento e oitenta) dias.

Decreto do Governo do Estado do Paraná no 2.581 de 17 fev. 2004.

Para o caso dos PEMs, há uma maior liberdade na sua elaboração, permitindo aos técnicos elaboradores e seus munícipes propor formas de atuação municipal diferenciadas e com maiores chances de adequabilidade. Conciliar as potencialidades de diagnóstico, de participação popular, de envolvimento dos diversos agentes sociais e de liberdade propositiva é um dos ganhos maiores ao se combinar os princípios de cada uma das duas tipologias de plano.

A prática do planejamento nos municípios visa corrigir distorções administrativas, facilitar a gestão municipal, alterar condições indesejáveis para a comunidade local, remover empecilhos institucionais e assegurar a viabilização de propostas estratégicas, objetivos a serem atingidos e ações a serem trabalhadas. O planejamento é, de fato, uma das funções clássicas da administração científica indispensável ao gestor municipal. Planejar a cidade é essencial, é o ponto de partida para uma gestão municipal efetiva diante da máquina pública, onde a qualidade do planejamento ditará os rumos para uma boa ou má gestão, com reflexos diretos no bem-estar dos munícipes (Andrade et al., 2005). É também premente a preocupação com o comportamento das finanças municipais, que estabelecem relações entre receitas, despesas, investimentos e endividamentos (Santos e Ribeiro, 2004). Por outro lado, não podem ser esquecidas as variáveis socioambientais das cidades, que enfatizam a sustentabilidade urbana, o cenário de diversidade social que caracteriza as cidades e a importância de se priorizar a função social da propriedade. Considerando que tais questões podem ser mais significativas em um município que em outro, reproduzindo particularidades, é evidente que a metodologia de elaboração de um plano que não se vincule a determinações programáticas e jurídicas conta com mais chances de sucesso. Sob essa perspectiva, o PEM 
parece adequar-se mais facilmente a especificidades diversas. O PDM, por sua vez, com a obrigatoriedade de discutir, por exemplo, questões específicas do uso e ocupação do solo, tais como o combate a vazios urbanos e a subutilização de imóveis, focaliza esforços em questões de interesse recorrente no cenário urbano nacional, porém não de forma generalizada e única.

A despeito das mudanças impostas pelo Estatuto da Cidade, que vê o PDM como um instrumento de ordenamento das relações sociais sobre o espaço de todo o território de um município, este ainda é, na prática, elaborado a partir de uma visão reducionista e mais direcionado para o planejamento físicoterritorial. O PEM, por sua vez, tradicionalmente não trabalha essas questões, mesmo porque seu objetivo de resultados é pensado em um período mais curto de tempo, com impactos mais a curto prazo. Porém, ambos devem ter caráter integral e integrado, abordando múltiplas questões na área urbana e na área rural, com todas as dimensões compatibilizadas entre si, produzindo e com uma abordagem equilibrada entre elas.

Se, por um lado, o suporte legal sobre o qual o PDM é elaborado pode gerar generalizações entre realidades diferentes, por outro, pode também garantir maiores chances de implementação. A partir de determinações da Constituição Federal (1988) que já atribuem importância e obrigatoriedade ao plano diretor, observam-se avanços, se não na implementação de todas as suas diretrizes, no arcabouço legal capaz de garantir um referencial importante para o caso de defesa de interesses da sociedade.

Art. 182. A política de desenvolvimento urbano, executada pelo Poder Público municipal, conforme diretrizes gerais fixadas em lei, tem por objetivo ordenar o pleno desenvolvimento das funções sociais da cidade e garantir o bem-estar de seus habitantes.

§ 1ํ O plano diretor, aprovado pela Câmara Municipal, obrigatório para cidades com mais de vinte mil habitantes, é o instrumento básico da política de desenvolvimento e de expansão urbana...

No caso de um PEM, não se observam exigências legais dessa ordem; todavia, a decisão de um município em elaborar tal plano indica um interesse específico e um consenso entre agentes diversos de sua sociedade.

Diante das características de cada plano, da obrigatoriedade legal de realização de $\mathrm{PDMs}^{1}$ para muitos dos casos dos municípios brasileiros e da

\footnotetext{
${ }^{1}$ Segundo informativo do Plano Diretor Participativo no 05, de 24 de maio de 2006, do Ministério das Cidades, já foram concluídos $88 \%$ das 1.684 localidades obrigadas a elaborar o PDP. Todavia, o mesmo informe revela que apenas $30 \%$ dos processos conta com a participação popular.
} 
crescente valorização dos PEMS, este artigo sugere uma discussão a respeito de uma possível integração entre eles. As bases empíricas dela repousam nas experiências acadêmicas e profissionais dos autores em PDMs tal qual mais comumente entendido pela urbanística contemporânea e pela política urbana brasileira que procura implementar as diretrizes do Estatuto da Cidade e em iniciativas de planejamento estratégico aplicado à gestão urbana e municipal. O objetivo deste artigo é discutir a formatação de cada um desses instrumentos, seus potenciais e suas limitações.

Na seqüência, uma síntese do cenário urbano sobre o qual deve ser trabalhado o PDM e o PEM, as bases teórico-referenciais de cada um desses dois instrumentos de planejamento e, por último, uma discussão sobre a aplicação deles.

\section{Os planos e sua interface com o cenário urbano nacional}

Procuramos sintetizar alguns aspectos do cenário urbano brasileiro que possam influenciar a elaboração e aplicação dos planos aqui discutidos. Considerando a alternância e renovação de instrumentos utilizados pelo planejador nacional nestas últimas décadas, vê-se que o mesmo acontece com os objetos de estudo desses mesmos planos. Para melhor compreensão, dividimos em seis itens, a partir de uma retrospectiva empírica dos autores para a última década.

1. Os problemas urbano-ambientais das cidades permanecem os mesmos e se avolumam em termos de complexidade. Cabe ao planejador urbano conviver com esses mesmos problemas, agravados, e, portanto, mais difíceis de resolver. Ao se tomar como base os planos desenvolvidos há uma década e os que ora se observam, pode-se dizer que muitas das prioridades consideradas para um e outro permanecem as mesmas: saneamento, habitação, ocupação de áreas ambientalmente sensíveis e deficiência de serviços comunitários. A diferença principal estaria no agravamento desses temas para o caso dos planos presentemente elaborados.

2. O quadro de servidores públicos junto aos governos locais reduziu-se. O fato de se ter menos funcionários nas instituições de planejamento dos governos incrementa a dependência por serviços de acadêmicos ou de terceiros, podendo influir negativamente na implementação e continuidade das ações propostas. Ao mesmo tempo, cresce a demanda sobre os funcionários disponíveis devido à complexidade dos serviços. Tal fenômeno foi reconhecido pelas administrações públicas e o que se observa é que os planos hoje são feitos por empresas de consultoria e, em alguns poucos casos, por 
instituições acadêmicas. A maior ou menor participação da equipe de governo local implica uma maior ou menor viabilidade de implementação de um plano, seja ele um PDM ou um PEM.

3. A despeito da redução do quadro de funcionários nas prefeituras, a equipe responsável pelo planejamento, que fará a interface com a equipe de consultores ou de acadêmicos, tem agora mais capacidade e um maior volume de informações, na maioria informatizadas. Tal fato, garante um diferencial positivo para a elaboração de um plano.

4. Os recursos financeiros disponíveis para a elaboração de planos e, o que é mais complexo, para sua implementação, nos últimos 10 anos, foram reduzidos. É sabido que esse fato sempre foi recorrente nas administrações públicas brasileiras, porém parece ter ficado mais evidente nos últimos anos. Se tal fenômeno parece ter apenas aspectos negativos, vale lembrar que implica também uma maior competência de gestão por parte das administrações públicas, assim como uma busca por maior efetividade nas suas ações. Além disso, tal fato tem levado a uma busca incessante por parceiros externos ao poder municipal. Tal fato é mais ostensivo no caso do desenvolvimento de PEMs, que valorizam a participação do setor produtivo privado e conseqüentemente dos cidadãos de forma mais ampla.

5. A participação da comunidade agora é obrigatória. Se antes da aprovação do Estatuto da Cidade a participação da comunidade era importante, agora ela é obrigatória e se efetiva, com a realização de um plano diretor. De um modo geral, tem-se observado uma média de duas a três audiências públicas quando é realizado um plano diretor e, o que talvez seja ainda mais importante, seu desenvolvimento deve contar com grande publicização de suas ações e proposições. No caso de um planejamento estratégico, a despeito dele não contar com exigência legal de participação comunitária, acredita-se que é, também, um dos aspectos mais importantes de seu desenvolvimento, já que se fundamenta no consenso do maior número possível de parceiros.

A questão da participação comunitária tem implicado não apenas a imposição de um caráter necessariamente democrático ao planejamento, mas também uma mudança na maneira de se trabalhar. Ampliam-se não apenas os agentes envolvidos no processo de planejamento, mas, igualmente, os temas de interesse. Geralmente, os planos diretores trabalhados em período anterior aos anos 1980 e 1990 reduziam suas análises a setoriais de uso do solo, saneamento, sistema viário, transporte, habitação, saúde e educação (esses dois últimos, somente em termos da espacialização da rede). Atualmente, além destes, o plano diretor se obriga a trabalhar com novos temas 
e, o que é importante, de forma integrada. Os novos temas de trabalho do planejador incluem a geração de renda em comunidades carentes e a violência, que atualmente fazem parte obrigatória do planejamento urbano. No planejamento estratégico municipal, essas questões são tratadas como temáticas municipais, por exemplo, agricultura e rural; ciência, tecnologia e inovação; comércio; cultura; educação; esporte; habitação; indústria; lazer; meio ambiente; saúde; segurança; serviços; transporte; turismo; e entre outros de caráter mais específico para cada município.

6. Num cenário de redução do papel do Estado e valorização das regras do capital privado, entes públicos passam agora também a buscar mecanismos de competir em cenários regionais e, até mesmo, no internacional. As cidades talvez sejam as que melhor desenvolveram a capacidade de competir, buscando por recursos cada vez mais escassos e repassados sob o enfoque do mercado. Quando se tinha a figura de um Estado capaz de inverter recursos para ações de priorizações e mesmo de compensações regionais, relegava-se a competitividade e valorizava-se a capacidade da representação política para viabilizar a canalização de recursos (por exemplo, do governo federal). Hoje, reduziram-se as oportunidades de se obter recursos dos governos federal e estadual e ampliaram-se as oportunidades para atrair investimentos da iniciativa privada. Impôs-se a competitividade entre as cidades, dificultando ainda mais as chances de transformação dos municípios mais pobres e menos estruturados. A despeito dessas mudanças, a prática tem mostrado que os planos diretores ainda relutam em captar essa nova realidade e são construídos de forma a apresentar demandas ao poder público no sentido de universalizar o atendimento de serviços e infra-estruturas urbanas básicas. Na realidade, o principal interlocutor de um plano diretor, apesar de sua busca por envolver um maior número possível de agentes, permanece o poder público municipal, muitas vezes sem reconhecer sua incapacidade de inverter os recursos necessários. Ao contrário, os planejamentos estratégicos municipais têm na visão pragmática da disponibilidade do recurso a sua mais importante referência para os investimentos. Além disso, uma vez projetados os objetivos, as estratégias e as ações municipais, serão elaboradas as suas viabilidades, que podem ser financeiras e não-financeiras (sociais). Assim, com projetos e viabilidades formalmente expressos, a possibilidade de parcerias privadas é mais factível, pois os investidores podem mais facilmente visualizar os resultados.

A partir dessas considerações, que de forma bastante simplificada procuram sintetizar mudanças recentes no cenário urbano brasileiro, é possível 
observar os diferentes desempenhos entre um e outro instrumento do planejamento aqui estudado.

\section{Referenciais teóricos do plano diretor municipal (PDM)}

Os princípios que norteiam o plano diretor estão contidos no Estatuto da Cidade, onde esse plano está definido como instrumento básico para orientar a política de desenvolvimento e de ordenamento da expansão urbana do município. É obrigatório para os municípios: com mais de 20 mil habitantes; integrantes de regiões metropolitanas e aglomerações urbanas; com áreas de especial interesse turístico; situados em áreas de influência de empreendimentos ou atividades com significativo impacto ambiental na região ou no país.

O plano diretor municipal (PDM) se apresenta hoje como um instrumento básico do planejamento urbano nacional, repetindo momentos na história urbana recente que valorizou esse tipo de iniciativa. A sua valorização, observada nos anos 1990 e 2000, é fruto de dois fatores que têm norteado uma possível política urbana nacional. Primeiramente, a Constituição de 1988 que repassa para o plano diretor a implementação da função social da propriedade. Assim, o legislador nacional, reforçando a importância do PDM, demonstra a crença de que mudanças na estrutura fundiária, por exemplo, só poderiam ser implementadas se previamente definidas por um estudo técnico. ${ }^{2}$ Ainda restam análises a serem feitas sobre a real capacidade desses entendimentos de reverter interesses do mercado imobiliário e se o caminho para a implementação de instrumentos legais para efetivá-los necessita verdadeiramente de planos abrangentes como um PDM. Outro fenômeno que explica a valorização contemporânea de um PDM é, mais uma vez, a Constituição Federal, agora ao adotar uma política de descentralização político-administrativa, assim como uma valorização do ente municipal, que necessita ser capacitado e possuidor de bases técnicas referenciais para sua gestão. Mais uma vez, o PDM aparece como o instrumental capaz de atender a essa demanda. De um ponto de vista mais pessimista pode ainda incluir um terceiro fator que justifique a valorização atual dos PDMs. De fato, durante a elaboração da Constituição Federal de 1988, as questões mais polêmicas foram propositadamente postergadas e submetidas à elaboração de leis específicas. No caso das questões polêmicas de caráter urbano, acreditou-se que o Estatuto da Cidade - com a

${ }^{2} \mathrm{O}$ PDM, ainda que formulado com um forte propósito participativo, constitui um documento técnico, caracterizado pelo entendimento da equipe responsável pela sua elaboração. 
Constituição já em debate - poderia avançar para garantir o interesse maior no uso do solo e dos bens urbanos. Tal instrumento legal aprimora os instrumentos de controle social da cidade e, por sua vez, igualmente repassa ao PDM a adequação de suas diretrizes para cada uma das realidades urbanas brasileiras. Ainda que não se tenha uma perspectiva histórica para avaliação do avanço permitido pelos PDMs nesse sentido, arrisca-se dizer que, mais uma vez, questões importantes são postergadas, agora para legislações municipais de caráter complementar. Parte de uma política urbana nacional que valoriza a participação popular, não necessariamente de forma deliberada, os PDMs têm sido incentivados e têm consumido uma grande parcela dos recursos e esforços das gestões locais. Se computados os avanços no envolvimento da população na discussão daquilo que é de seu interesse, o PDM, em alguns casos, apresenta resultados positivos e singulares. Do mesmo modo, se considerado que para muitos municípios constitui um primeiro avanço no ordenamento de seu território, o PDM pode justificar sua renascença nas duas últimas décadas. Todavia, após o período de realização quase generalizada de PDMs nos anos 1970, começam a haver sinais de críticas e de desconfiança desse instrumento. "A idéia do plano diretor existe no Brasil, pelo menos desde 1930... Desde então a idéia do plano diretor alastrou-se entre nós com grande intensidade ... é impressionante como um instrumento que nunca existiu na prática, possa ter adquirido tamanho prestígio por parte da elite do país" (Villaça, 2005). Uma das críticas aos PDMs - sem aqui discutir seus aspectos metodológicos e operacionais - é a que diz respeito à amplitude de seus propósitos para uma realidade complexa e mutante que é a realidade urbana da atualidade. "Os planos diretores fracassaram não só em São Paulo, mas em todo o Brasil e na América Latina. Fracassaram não só porque eram falhos, mas porque tomaram os desejos pela realidade" (Singer, 1995, citado em Villaça, 2005).

Aqui não se coloca em questão a validade de instrumentos de conhecimento e de gestão, como o PDM, para o desenvolvimento de uma cidade e para a divisão de seus ganhos da forma mais eqüitativa possível. Ao contrário, um dos objetivos deste artigo é iniciar um debate sobre a possibilidade de conciliar novas técnicas a instrumentos já ensaiados, agregando-lhes perspectivas de outras ciências e práticas, como é o caso do planejamento estratégico com origens na administração empresarial. As cidades brasileiras passam e passarão por mudanças profundas, que poderão garantir um futuro de desenvolvimento equilibrado. Também poderão universalizar o direito à moradia digna em ambiente saudável para todos os seus munícipes. Para tanto, elas têm que contar com fontes estáveis e seguras de financiamento para o desenvolvimento urbano e rural, indispensáveis para que possam se manter e se 
expandir de forma adequada e democrática. Para que isso seja possível, os cidadãos terão que enfrentar um grande desafio nos próximos anos: instituir formas de planejamento e controle do território municipal. Juntos, a gestão urbana, a gestão municipal e os munícipes podem utilizar os potenciais e limites do seu meio físico, as potencialidades abertas pela existência de redes de transporte e logística em seus territórios. Planejar democraticamente o futuro da cidade incorporando nessa discussão os diversos agentes sociais, econômicos e políticos que a compõem, buscando compromissos e definindo ações prioritárias; esse é o desafio que o Estatuto da Cidade impõe aos planos diretores.

Os problemas do plano diretor municipal estão mais relacionados com as temáticas territoriais: desenvolvimento econômico; reabilitação de áreas centrais da cidade e sítios históricos; avaliação e atividades em áreas rurais; políticas habitacionais; regularização fundiária; transporte e mobilidade; saneamento ambiental; estudos de impactos de vizinhança; instrumentos tributários e de indução de desenvolvimento; desenvolvimento regional; e outras questões de ocupação do solo. Essas temáticas podem ser abordadas em quatro etapas: elaborar leituras técnicas e comunitárias para identificar, mapear e entender a situação do município; formular e pactuar propostas com perspectiva estratégica; definir instrumentos de viabilidades dos objetivos e estratégias municipais; e sistema de gestão e planejamento do município (Cidades, 2004). Essas questões de ocupação do solo ou estudos físico-territoriais podem contemplar ainda: concentração/descentralização de funções; formas espaciais urbanas; circulação urbana, transporte coletivo; uso e ocupação do solo; distribuição dos serviços públicos; e, sobretudo, propostas de apropriação mais coletiva do capital da cidade. Todas as questões pertinentes a esse plano têm se constituído em dilemas por décadas, envolvendo múltiplos conceitos e interesses nem sempre coerentes, extrapolando temáticas físico-territoriais (Villaça, 1999).

\section{Referenciais teóricos do planejamento estratégico municipal (PEM)}

Os fundamentos e as premissas para elaborar o planejamento e os planos municipais propostos estão relacionados com temas como a disponibilidade de informações, conhecimentos específicos do município e de sua estrutura de gestão, possíveis ações estratégicas, postura estratégica dos gestores locais, empreendedorismo e desejo de inovação.

O planejamento estratégico municipal (PEM) é um processo dinâmico e interativo para determinação dos objetivos, estratégias e ações do município. É elaborado por meio de técnicas administrativas diferentes e complementa- 
res, envolvendo de forma ativa os diversos atores sociais do espaço trabalhado. É formalizado para articular políticas federais, estaduais e municipais para produzir resultados no município e gerar qualidade de vida adequada aos seus munícipes. É um projeto urbano global que considera as múltiplas temáticas municipais e valoriza a forma participativa e contínua de pensar o município no presente e no futuro (Rezende e Castor, 2006).

Segundo Pfeiffer (2000) o PEM é um instrumento de gerenciamento que, como qualquer outro, tem um único propósito: tornar a gestão de uma cidade mais eficiente. $\mathrm{O}$ enfoque estratégico no desenvolvimento local diminui as indecisões e favorece as transformações econômicas, sociais e políticas para tratar com coerência a multiplicidade de iniciativas sobre o município, buscando um consenso entre os múltiplos atores (inclusive o governo) na seleção de um futuro desejável e factível (Llona et al., 2003). Para Lopes (1998) o PEM tem como objetivo principal a coordenação dos vários níveis e funções estratégicas de uma cidade em um projeto global, considerando a missão, as estratégias, o orçamento e o controle dos objetivos das ações municipais. Motta (2004), por sua vez, reitera que o planejamento da cidade é uma forma de aprendizado sobre as demandas e necessidades externas e a capacidade de resposta da administração municipal para revelar expectativas e referências de valor, essenciais a um grupo de trabalho.

Inúmeras situações podem levar uma cidade a formular um planejamento estratégico. Um exemplo é a necessidade de criar um consenso sobre um modelo de futuro da cidade de acordo com as mudanças que são produzidas ao redor da mesma, de dar respostas às crises, à recessão dos setores básicos da economia territorial e, também, de perseguir uma maior coesão e integração territorial. Essas são as situações que podem facilitar a gestão estratégica das cidades.

Os conceitos advindos do planejamento empresarial, assim compreendidos pela Harvard Business School, podem ser adotados pelos governos locais em razão de as cidades estarem submetidas às mesmas condições e desafios que as empresas (Arantes et al., 2000). O PEM surge como uma ferramenta para afrontar a problemática urbana e possibilitar agir sobre as populações e os territórios; a desigualdade, pobreza e informalidade; as infra-estruturas urbanas e de mobilidade; o espaço público; a competitividade e a nova economia da cidade e seu relacionamento com a gestão urbana; a sustentabilidade; e, finalmente, sobre a construção de um projeto de cidade. A partir da construção de um consenso o PEM converte-se num processo permanente de desenvolvimento (Cideu, 2004).

Antes de iniciar a elaboração de um projeto de PEM em uma cidade é necessário dedicar tempo a sua organização, onde podem ser trabalhadas as seguintes atividades: definição da metodologia do projeto; constituição da 
equipe multidisciplinar e comitês; divulgação do projeto (na prefeitura e no município); capacitação das pessoas envolvidas; elaboração dos planos de trabalho; e formalização dos procedimentos de gestão do projeto PEM.

A equipe multidisciplinar é uma parte fundamental para o sucesso metodológico do projeto coletivo e participativo. Pode ser composta pelos seguintes papéis: patrocinador, gestor, equipe de servidores municipais e munícipes. Todas as atividades do projeto PEM devem ser elaboradas pelos componentes da equipe multidisciplinar atuando de forma interdisciplinar e coletiva. Essa equipe também pode ser chamada de comitê de trabalho, composto pelos seguintes grupos de pessoas: conselho do município, conselho municipal ou conselho da comunidade local; conselho diretor ou patrocinadores do PEM; comitê gestor, comitê executivo, ou equipe multidisciplinar coordenadora do PEM; grupos de trabalho, comissões especializadas ou conselhos setoriais; e assessores externos. Após nomear as pessoas envolvidas, será necessário capacitar as mesmas e planejar as suas atividades.

Todo projeto deve ter uma metodologia adequada, viável, dinâmica e inteligente. Como o PEM é do município, ele requer uma metodologia coletiva para sua elaboração e implementação. Pode ser uma abordagem organizada para alcançar o sucesso do projeto por meio de passos preestabelecidos. Para Matus (1997), que trabalha o planejamento estratégico situacional, a metodologia contempla principalmente: levantamento da situação da cidade (diagnóstico associado à análise setorial); construção de uma matriz de problemas e operações; elaboração do planejamento modular; transformação do plano em instrumento; atribuição de responsabilidades aos organismos públicos; e interação do planejamento político com o planejamento econômico e técnico. Recomenda também uma gerência por operações e orçamento por programas. Depois sugere as tecnologias por planejamento, os sistemas de suporte às decisões e de prestações de contas, um sistema de avaliação e revisão permanente. E, por último, uma equipe de reflexão que articula a análise estratégica com a análise de problemas e atualiza permanentemente as linhas estratégicas de ações municipais.

Para Lopes (1998), uma metodologia de PEM pode ser dividida em organização, elaboração do plano com base na análise do diagnóstico da cidade, implementação e monitoramento e programa de comunicação. Para Pfeiffer (2000), essa metodologia pode conter as seguintes fases: preparação; análise do meio ambiente e da própria prefeitura; estruturação do plano por meio da visão; a missão, a estratégia, a definição de objetivos; formulação dos projetos; formulação do plano; implementação; e avaliação. Wheeland (1993) propõe que se faça um diagnóstico da cidade, seguido das seguintes fases: planejamento e orçamento; envolvimento dos stakeholders; definição da equi- 
pe para análises; definição dos consultores para projetar e executar o processo; obtenção de soluções criativas; definição das estratégias; aprovação e aceitação do plano. E, finalmente, Motta (2004) reitera as análises racionais e as intenções pessoais, definindo a visão, produzindo as estratégias (validando os cenários e a visão) e as decisões estratégicas.

De forma análoga, Rezende e Castor (2006) recomendam uma metodologia com as seguintes fases: análises estratégicas; diretrizes estratégicas; estratégias e ações municipais; e controles municipais e gestão do planejamento. As análises estratégicas diagnosticam as análises do município, externas ao município e da administração municipal. As diretrizes estratégicas contemplam diretrizes do município e da administração municipal. As diretrizes do município podem ser divididas nas subfases: visão do município; vocações do município; valores ou princípios do município e dos cidadãos; e objetivos municipais. No que diz respeito à prefeitura, são contempladas as subfases: missão municipal, atividades municipais, políticas municipais e procedimentos organizacionais municipais. As estratégias municipais são caminhos ou alternativas para alcançar os objetivos municipais. As ações municipais oportunizam as diversas possibilidades ou alternativas para realizar as estratégias municipais, levando em conta as suas viabilidades (financeiras e não-financeiras, sociais), os recursos, as leis e, acima de tudo, a vontade da comunidade local. Os controles municipais e a gestão do planejamento definem padrões para medição de desempenho e formalizam o acompanhamento, a correção de desvios e a garantia do cumprimento do PEM. Enfatizam o estabelecimento de indicadores para posterior medição, acompanhamento e avaliação. Os municípios sofrem controles por meio de instrumentos legais onde o PEM deve respeitar as legislações vigentes, podendo incluir, ainda, auditorias municipais, indicadores, sistemas de informação e conhecimentos.

Apesar de se ter difundido nas literaturas brasileira e internacional o fato de que um PEM direciona para a competitividade estratégica, acredita-se que a sua metodologia não pode enfatizar os componentes mercantis ou a competitividade entre cidades, e muito menos a busca desenfreada por investimentos. Ao contrário, um PEM deve considerar as questões socioambientais do município e debatê-las democrática e participativamente, legitimando-as em consensos.

\section{Conclusão}

Na política urbana nacional, instrumentos de planejamento ora são valorizados, ora são esquecidos por planejadores e gestores municipais na prática ur- 
bana nacional. Metodologias e instrumentos diversos têm sido utilizados como forma de planejamento urbano no Brasil de forma cíclica e, em alguns casos, com pequenas mudanças. De fato, ora valoriza-se a estrutura municipal pública, ora os interesses públicos majoritários, ora defendem-se os interesses do setor privado. Renovam-se e alternam-se também as práticas de participação popular - em um momento acredita-se na necessidade de uma valorização da participação direta da população; em outro, defende-se o reforço das estruturas da democracia representativa; e, em outros ainda, adotam-se posturas tecnocráticas. Em todas essas situações, ambos os casos de planejamento aqui descritos podem ser adotados, mostrando tratar-se mais de uma questão de forma que do modelo adotado.

O que se observa é que sucessos e fracassos precedentes na gestão municipal, entre outros fatores, determinam a forma que será adotada num plano diretor ou num plano estratégico municipal. O fracasso de planos diretores que priorizaram o ordenamento do uso do solo, por exemplo, justificam a escolha de formas de planejamento que valorizem a dinâmica mais integrada da ação pública. Do mesmo modo, a demora na visualização de resultados quando de planos diretores que obtiveram sucesso na imposição de modelos de ocupação físico-territorial - tem levado administradores públicos e setor privado a optarem por um planejamento de resultado mais imediato, conforme proposto pelo PEM.

A questão processual na ação do planejamento - e que envolve diferentes atores do município - tem sua importância não apenas no resultado daquilo para o qual foi proposto, mas sim de sua elaboração; ou seja, a importância de um PDM ou de um PEM pode ser sua simples realização, sem mesmo considerar seus resultados. O importante é o aprendizado da participação popular, da compreensão técnica da realidade e da comunicação entre agentes com interesses diversos. A consciência de que esses são fatos relevantes, num reconhecimento do valor do processo antes mesmo de se reconhecer o resultado, pode igualmente diminuir possíveis constatações de que a realidade, ironicamente, não respeita o planejado.

Num debate que ainda carece de maiores discussões, ressalta-se a importância da fase de monitoramento de um PDM ou de um PEM. Para o primeiro caso, há sinais dessa prática pelo governo federal, mas é o controle do que fora consensuado na esfera municipal pela comunidade local que necessita ser adotado. Logo, para qualquer plano, incluindo o PEM, reitera-se a exigência de continuidade, de fiscalização e de reavaliações.

Como o objetivo deste artigo foi contribuir para a discussão da formatação e a integração dos instrumentos PDM e PEM, considerando os seus potenciais, limitações, modelos e variáveis, a partir de estudos de casos que contaram 
com a participação dos autores, observou-se que esse desafio é inegável. Também é inquestionável que esses instrumentos podem se tornar inexoráveis instrumentos de gestão das cidades.

Em relação às contribuições deste artigo, elas estão direcionadas para o meio acadêmico e para as cidades que desejam questionar sua gestão e seus planejamentos. Destacam-se como exemplos a serem explorados alguns aspectos do cenário urbano brasileiro que influenciam a elaboração e aplicação do plano e planejamento aqui discutidos, para motivar outros estudos teóricos.

A discussão também pode facilitar pesquisas aplicadas em outras cidades para entender e sugerir alternativas para os seus desafios emergentes de planejamento e de gestão que envolvem seus munícipes, servidores municipais, gestores locais e demais interessados na cidade e nos municípios vizinhos.

Para as cidades, esta discussão pode contribuir com a integração e as relações entre o PDM e o PEM, permitindo um entendimento mais abrangente desses dois instrumentos similares.

\section{Referências bibliográficas}

ALPHANDÉRY, P. et al. O equívoco ecológico. São Paulo: Brasiliense, 1992.

ACSELRAD, H. (Org.). A duração das cidades: sustentabilidade e risco nas políticas urbanas. Rio de Janeiro: DP\&A, 2001.

ANDRADE, N. A. et al. Planejamento governamental para municípios: plano plurianual, lei de diretrizes orçamentárias e lei orçamentária anual. São Paulo: Atlas, 2005.

ARANTES, O.; VAINER, C.; MARICATO, E. A cidade do pensamento único: desmanchando consensos. 3. ed. Petrópolis: Vozes, 2000.

BORJA, J. Barcelona: um modelo de transformación urbana. Quito: Programa de Gestión Urbana, 1995. Série Gestión Urbana, v. 4.

BRASIL. Constituição Federal, 1988.

CIDADES (MINISTÉRIO DAS CIDADES). Plano diretor participativo: guia para elaboração pelos municípios e cidadãos. Brasília: Confea, 2004.

CIDEU (Centro Iberoamericano de Desarrollo Estratégico Urbano). 10 años de la Planificación Estratégica en Iberoamérica. Barcelona: Cideu, 2004.

ESTATUTO DA CIDADE. Guia para implementação pelos municípios e cidades. 2. ed. Brasília: Câmara dos Deputados, Coordenação de Publicações, 2002. 
JACOBI, P. Meio ambiente e sociedade. In: O município no século XXI: cenários e perspectivas. São Paulo: Fundação Prefeito Faria Lima - Cepam, 1999. Edição especial.

LLONA, M.; LUYO, M.; MELGAR, W. La planificación estratégica del desarrollo local en Perú: análisis de casos. Lima: Escuela para el Desarrollo, 2003.

LOPES, R. A cidade intencional: o planejamento estratégico de cidades. Rio de Janeiro: Mauad, 1998.

MATUS, C. Planejamento, orçamentos e gerência. Revista ABOP, n. 29/88. Brasília, 1987.

MOTTA, P. R. Gestão estratégica. In: VERGARA, S. C.; CORRÊA, V. L. A. Propostas para uma gestão pública municipal efetiva. 2. ed. Rio de Janeiro: FGV, 2004.

PARANÁ. Decreto do governador nํㅜ 2.581, de 17 fev. 2004.

PFEIFFER, P. Planejamento estratégico municipal no Brasil: uma nova abordagem. Brasília: Enap, out. 2000. Textos para Discussão, n. 37.

REZENDE, D. A.; CASTOR, B. V. J. Planejamento estratégico municipal: empreendedorismo participativo nas cidades, prefeituras e organizações públicas. 2. ed. Rio de Janeiro: Brasport, 2006.

SANTOS, R. S.; RIBEIRO, E. M. Poder municipal: participação, descentralização e políticas públicas inovadoras. In: ENCONTRO DE ADMINISTRAÇÃO PÚBLICA E GOVERNANÇA DA ANPAD, 1., 2004, Rio de Janeiro. Anais... Rio de Janeiro: Enapg, 2004.

VAINER, A.; ALBUQUERQUE, J.; GARSON, S. Manual de elaboração: o passo a passo da elaboração do PPA para municípios. 2. ed. Brasília: Ministério do Planejamento, Orçamento e Gestão. Banco Nacional de Desenvolvimento Econômico e Social, 2005.

VILLAÇA, F. Dilemas do plano diretor. In: O município no século XXI: cenários e perspectivas. São Paulo: Fundação Prefeito Faria Lima — Cepam, 1999. Edição especial.

. As ilusões do plano diretor. Disponível em: <www.usp.br/fau/fau/galeria/paginas/ index.html>. Acesso em: 15 dez. 2005.

WHEELAND, C. M. Citywide strategic planning: an evaluation of Rock Hill's. Public Administration Review, Washington, v. 53, n. 1, p. 65-72. Jan./Feb. 1993. 